\title{
A Video Interview of Buz Brock
}

\author{
Bruce Mizrach* \\ Rutgers University
}

September 2004

\begin{abstract}
This article is a video presentation of an interview with Buz Brock at the 12th SNDE conference in Atlanta Georgia on March 12, 2004. The interview includes 15 questions on topics ranging from nonlinear dynamics, ecological modeling, and heterogenous agents.
\end{abstract}

Keywords: nonlinear dynamics; heterogenous agents; ecology; bio-diversity.

JEL Classification: C61.

\footnotetext{
* Mizrach is with the Department of Economics, Rutgers University, New Brunswick, NJ 08901. e-mail: mizrach@econ. rutgers.edu, (732) 932-8261 (voice) and (732) 932-7416 (fax). I would like to thank Blake LeBaron and Doyne Farmer for helpful discussions. I would like to thank Jerry Dwyer of the Atlanta Federal Reserve Bank for arranging for this convesation to be videotaped, and Fred Willis for filming the interview.
} 


\section{Introduction}

William A. (Buz) Brock is the Vilas Research Professor of Economics at the University of WisconsinMadison where he has taught since 1975. His honors include being a Fellow of the Econometric Society, a Distinguished Fellow of the American Economic Association, a member of the American Academy of Arts and Sciences, and selection to the National Academy of Science.

Buz has been a leading voice in the field of nonlinear dynamics since his (1986) work on random versus deterministic systems. Buz was the plenary speaker at the 12 th annual Society for Nonlinear Dynamics Conference, and he was gracious enough to agree to an interview on the morning of March 12, 2004. I had sent Buz the questions prior to our meeting.

In two previous interviews of Buz, Woodford (2000) and Colander, Holt and Rosser (2004), both of the interviewers expressed that Buz's enthusiasm did not come through adequately in a transcript. I am extremely grateful that the Federal Reserve Bank of Atlanta was able to videotape our conversation. I hope this video interview is informative and shows Buz's deep love for economics.

\section{Background and motivation}

1. I find the term "chaos" has so many connotations that I try to avoid it. How do you reply when people say Buz Brock has been working on chaos? Do you like the term? How would you describe this part of your research? Can you relate it to the broader literature on complexity?

2. When did you first become aware that simple nonlinear models could have very complicated solutions?

3. Why should a person in macroeconomics or industrial organization read this literature? What about policy makers and learned people in general?

4. Have economic events like the 1987 stock market crash or the collapse of the Argentine economy influenced the way you think? Do you keep track of current events in the macroeconomy and financial markets?

\section{Literature}

5. Your first published paper $(J E T, 1986)$ in the field of nonlinear dynamics was titled "Distinguishing Random and Deterministic Systems." Do you believe now that it is a useful question to 
ask? Do you think that economists could ever identify a deterministic system, even if they could measure it accurately? Several papers in the literature claim to have found chaotic dynamics. Are they wrong?

6. Is determinism even a useful thought experiment for economics? For example, if the microstructure of the stock market led to 30-year cycles, couldn't we just change it?

7. Your most widely cited paper in the field is your work on the test for nonlinear dependence called the BDS (1996) statistic. Could you tell us why the paper took so long to be published? Do you think that the paper has gotten sufficient recognition?

8. Do you follow any of the other developments in the empirical literature on nonlinear time series. The most widely cited paper at SNDE is Hamilton's (1989) work on Markov switching. A close second is Engle (1982) and Bollerslev's (1986) work on GARCH. What is your assessment of this work? Do you think measurement has gotten ahead of theory?

9. You have written a number of papers on models with heterogenous agents. What do you think is the principal contribution?

10. Rosario N. Mantegna and H. Eugene Stanley write in their book An Introduction to Econophysics (1999) that "... in the study of economic systems, it is possible to investigate the system at different scales, but it is often impossible to write down the 'microscopic' equation for all the economic entities interacting within a given system. Statistical physics concepts... permit an understanding of the global behavior of economic systems without first having to work out a detailed microscopic version of the same system..." Do you agree with their view? What do you think of the econophysics literature in general?

11. Is your most recent work on ecology and bio-diversity influenced by your prior work in nonlinear dynamics?

\section{The future}

12. What do you think is the most important unsolved problem in the field of nonlinear dynamics?

13. If you were starting your career all over again, what would you study? Would it be economics?

14. What papers of yours do you think will be read 30 years from now?

15. What advice would you have for a student about to begin graduate study in economics? 


\section{References}

Bollerslev, T., (1986), "Generalized autoregressive conditional heteroskedasticity," Journal of Econometrics 31, 307-27.

Brock, W.A., (1986), "Distinguishing random and deterministic systems," Journal of Economic Theory 40, 68-195.

Brock, W. A., W.D. Dechert, B. LeBaron, and J.A. Scheinkman, (1996), "A test for independence based on the correlation dimension," Econometric Reviews 15, 197-235.

Colander, D.C., R.P.F. Holt, and J. B. Rosser, Jr., (2004), The Changing Face of Economics: Conversations with Cutting Edge Economists, Ann Arbor: U. of Michigan Press, 157-82.

Engle, R., (1982), "Autoregressive conditional heteroscedasticity with estimates of the variance of UK inflation," Econometrica 50, 987-1007.

Hamilton, J., (1989), "A new approach to the economic analysis of nonstationary time series and the business cycle," Econometrica 57, 357-384.

Mantegna, R.N. and H. E. Stanley, (1999), An Introduction to Econophysics: Correlations and Complexity in Finance, Cambridge: Cambridge U. Press.

Woodford, M., (2000), "An Interview with William A. Brock," Macroeconomic Dynamics 4, 108-38. 